\title{
Prêmio Prof. Heonir Rocha 2011
}

O Jornal Brasileiro de Nefrologia (JBN) tem a satisfação de apresentar os resultados do Prêmio Heonir Rocha 2011. Este ano, o artigo vencedor foi "Geografia da diálise peritoneal no Brasil: análise de uma coorte de 5.819 pacientes (BRAZPD)", de autoria da Dra. Natália Maria da Silva Fernandes e colaboradores, selecionado dentre os artigos originais publicados nas edições de Jun/Dez de 2010 - Vol. 32 e Mar/Jun de 2011 - Vol. 33.

Dra. Natália graduou-se em Medicina pela Universidade Federal de Juiz de Fora (UFJF) em 1993 e seguiu para São Paulo, onde fez residência em Clínica Médica e Nefrologia e Mestrado na Universidade Federal de São Paulo (UNIFESP). Retornou à UFJF onde obteve o título de Doutora e é professora da Faculdade de Medicina. Trabalha como médica Nefrologista na Fundação IMEPEN - Instituto Mineiro de Estudo Pesquisa em Nefrologia e pesquisadora no NIEPEN - Núcleo Interdisciplinar de Estudos, Pesquisas e Tratamento em Nefrologia, da UFJF. Atualmente, Dra. Natália encontra-se na Universidade de Leiden, onde está fazendo pós-doutorado em Epidemiologia.

$\mathrm{O}$ artigo vencedor é resultado de uma grande iniciativa chamada The Brazilian Peritoneal Dialysis Multicenter Study (BRAZPD). Trata-se de um estudo de coorte prospectivo envolvendo mais de cem centros de diálise peritoneal do Brasil. É o maior estudo já realizado em diálise peritoneal no mundo. Nesta edição do Prêmio Heonir Rocha, o BRAZPD emplacou dois artigos entre os cinco primeiros colocados (ver Quadro).

O corpo editorial do JBN parabeniza a todos os autores participantes pela excelente qualidade dos trabalhos. Estamos confiantes de que este nível de excelência será mantido na próxima edição do Prêmio.

Prof. Dr. Paulo Novis Rocha

Coeditor do Jornal Brasileiro de Nefrologia

\footnotetext{
Prêmio HeOniR Rocha 2011: os cinco PRIMEIROS Colocados

1. Fernandes NMS, Chaoubah A, Bastos K, Lopes AA, Divino-Filho JC, Pecoits-Filho R, et al. Geografia da diálise peritoneal no Brasil: análise de uma coorte de 5.819 pacientes (BRAZPD). J Bras Nefrol 2010;32(3):268-274.

2. Freitas TVS, Ono G, Corrêa L, Gomes PS, Galante NZ, Tedesco-Silva H, et al. Manifestações clínicas e evolução da infecção pelo vírus da influenza $A(H 1 N 1)$ em receptores de transplante renal. J Bras Nefrol 2011;33(2):136-141.

3. Lopes RA, Neves FAR. Metanálise de estudos de bioequivalência: a intercambiabilidade de genéricos e similares que contêm Hidroclorotiazida é possível, mas não àqueles com Maleato de Enalapril. J Bras Nefrol 2010;32(2):173-181.

4. Grincenkov FRS, Fernandes N, Chaoubah A, Bastos K, Qureshi AR, Pécoits-Filho R, et al. Fatores associados à qualidade de vida de pacientes incidentes em diálise peritoneal no Brasil (BRAZPD). J Bras Nefrol 2011;33(1):38-44.

5. Moraes TP, Fortes PCN, Ribeiro SC, Riella MC, Pecoits-Filho R. Análise comparativa de biomarcadores do metabolismo de glicose e lipídeos em pacientes não diabéticos em hemodiálise e diálise peritoneal. J Bras Nefrol 2011;33(2):173-179.
}

O Prêmio Heonir Rocha é concedido ao melhor artigo original publicado no JBN nos últimos 12 meses. O prêmio consiste no custeio (inscrição, passagens e hospedagem) da participação do pesquisador principal no Congresso Americano de Nefrologia. 


\section{EdITORIAL | EdITORIAL}

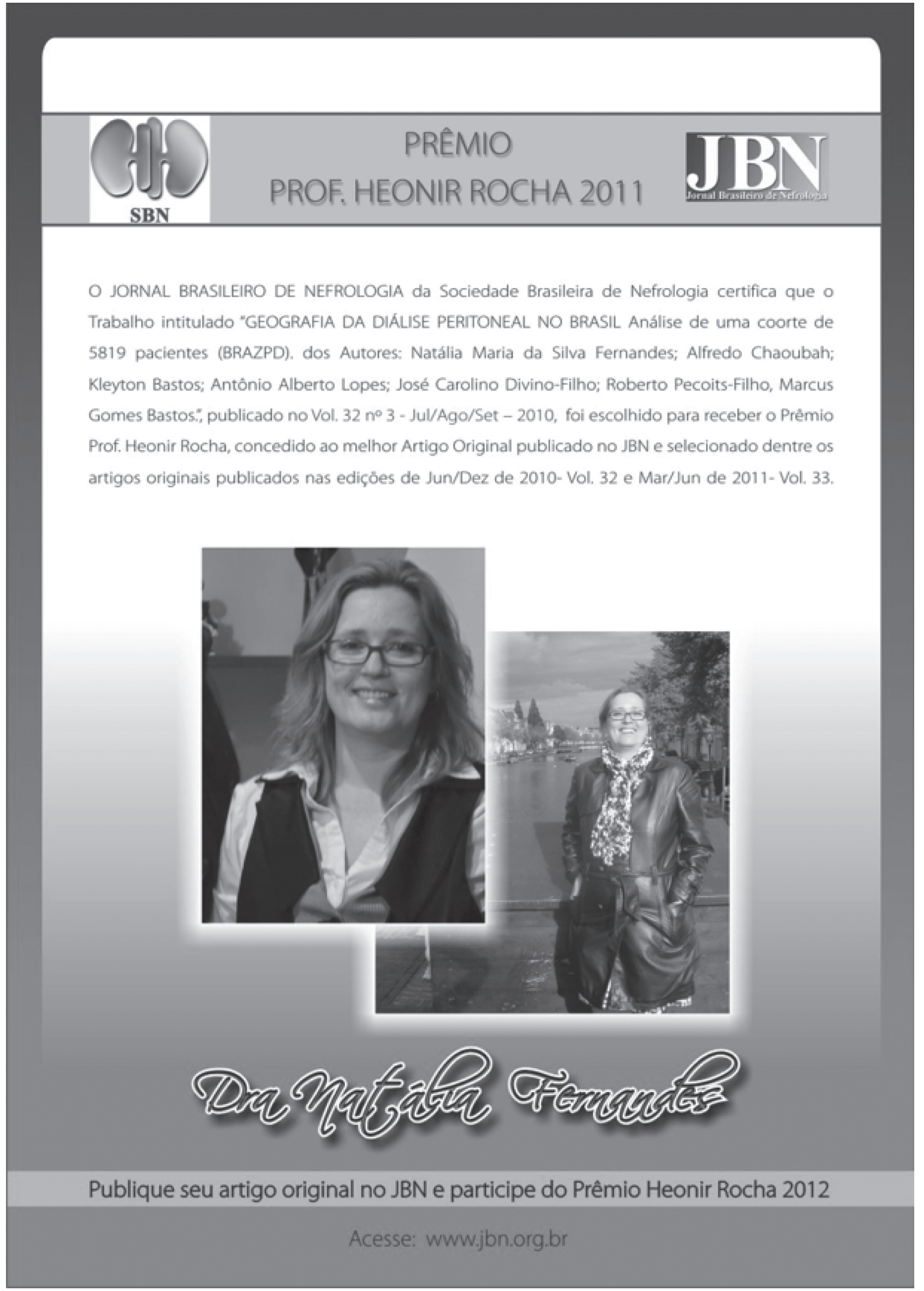

